\title{
EDITORIAL
}

\section{Let's not forget: the GOLD criteria for COPD are based on post-bronchodilator FEV1}

\author{
P.J. Sterk
}

\begin{abstract}
One of the major steps forward in the field of chronic obstructive pulmonary disease (COPD) has been the recent global consensus on the definition, classification and management of the disease. This so-called "GOLD" guideline is based on international consensus meetings held since 1998, which have resulted in detailed recommendations, as published in 2001 [1] and updated in 2003 [2]. The impact of such consensus cannot easily be overestimated. Not only is it a landmark with regard to providing reliable and up-to-date knowledge about this disease, but it also enables worldwide harmonisation of epidemiological, clinical and experimental research studies in patients with COPD. The latter is essential for the smooth comparison of results and, therefore, for further advances in the field.
\end{abstract}

\section{Using GOLD criteria}

COPD is a heterogeneous disease with various clinical presentations. The basic abnormality in all patients with COPD is airflow limitation that is not fully reversible. Therefore, the GOLD experts have defined the disease based on spirometric criteria by using the forced expiratory volume in one second (FEV1) and its ratio to the forced vital capacity (FVC). The main criterion for COPD is a FEV1/FVC ratio $<70 \%$. Subclassification into mild, moderate, severe and very severe disease is achieved by including various levels of FEV1 as percentage of predicted value [2]. Both versions of the GOLD report state in the body of the text that these spirometric criteria refer to post-bronchodilator values [1, 2].

Over the last few years, an increasing number of articles on COPD published in the European Respiratory Journal [3-5], as well as in other respiratory journals [6-9], have indeed used the GOLD criteria for the selection of study patients, and this is to be welcomed. However, when studying these papers it is not readily apparent whether the GOLD criteria have been applied in the appropriate way. Several studies have applied the GOLD cut-off values for FEV1 and FEV1/FVC by using spirometric measurements that were apparently obtained prior to the administration of a bronchodilator [3, 6-8]. Few studies explicitly deal with this issue by either adequately using post-bronchodilator values [9] or by stating that, in contrast to GOLD recommendations, spirometry was performed pre-bronchodilator only [4]. Other studies have chosen to report the reversibility of spirometry after a bronchodilator in conjunction with pre-bronchodilator values, but they have not specifically mentioned whether pre- or post-bronchodilator values were used for GOLD classification [5].

Therefore, the application of GOLD criteria does not seem

Correspondence: P.J. Sterk, Dept of Pulmonology, C3-P, Leiden University Medical Center, Albinusdreef 2, P.O. Box 9600, NL-2300 RC Leiden, the Netherlands. Fax: 31 715154691. E-mail: erj@lumc.nl to be uniform among investigators in the field. This may not be unexpected. Obviously, it is not trivial to include postbronchodilator spirometry in the epidemiological setting, for example. However, we have to face the fact that in the absence of such measurements, it may not be possible to classify subjects into COPD and its GOLD severity stages.

\section{Ceiling of lung function}

The question then arises: can a pre-bronchodilator value of FEV1/FVC $<70 \%$ accurately define COPD? There seems to be pathophysiological reasons why it cannot! Airflow limitation can be variable, particularly in diseases such as asthma and also in patients with concurrent asthma and COPD [10]. The present working hypothesis is that the variable part of airflow limitation is mainly based on varying degrees of smooth muscle contraction, which can be reversed by administering an adequate dose of an inhaled bronchodilator. The GOLD consensus rightly states that the airflow limitation in COPD is primarily irreversible, featuring only a small reversible component.

In order to exclude the possibility that the observed airflow limitation can be fully overcome by smooth muscle relaxation, the GOLD criteria for COPD are based on postbronchodilator spirometry only. Rather than using criteria based on limited reversibility per se, which varies largely among patients with COPD due to predictable fluctuations in smooth muscle tone [11], establishing a lowered "ceiling" of lung function seems to be indispensable for defining COPD. One could even argue that a course of systemic steroids might be necessary to obtain the real ceiling of spirometry [12], although the GOLD consensus has apparently made a practical choice not to include this in their recommendations.

The use of a lung function ceiling in the criteria for the presence and severity of COPD has the additional advantage that there may not be a need for the patient to stop regular treatment with long-acting bronchodilators prior to the postbronchodilator spirometric measurements. Nevertheless, recommendations on the type, (cumulative) dose and administration of the bronchodilator are urgently needed. The GOLD report is not perfectly clear about this and it is to be hoped that future updates will provide detailed guidance.

\section{The right message?}

The distinction of pre- and post-bronchodilator spirometry may not merely be a methodological detail. Is there not a good chance that the use of pre-bronchodilator FEV1/FVC values for the definition of COPD leads to potential overdiagnosis and over-estimation of the severity of this disease? This may be particularly important in young adults [8] in whom reversible airflow limitation may not be uncommon. 
Are we on the right track by disseminating information into the public domain on the prevalence and severity of COPD in the absence of measuring post-bronchodilator spirometry? Could this not introduce confusion for governmental and public health authorities, just at a critical point in time at which consistent and founded messages on respiratory health are broadly needed [13]?

\section{Outlook}

The prospects of research into the aetiology, course and management of COPD are better than ever. This is mainly driven by bridging the novel advances in molecular medicine with the clinical and epidemiological findings in COPD [14]. These innovative concepts have introduced increasing levels of sophistication into COPD research today. Eventually, this will probably help us to develop a more accurate definition of COPD and of its sub-phenotypes. But what is the chance of success if we broaden the latest consensus criteria of this disease? The experts are saying that we should not, as the 2004 update of the ATS/ERS standards for the diagnosis and treatment of patients with COPD (that will be published in the $E R J$ shortly) clearly sticks to the GOLD criteria based on post-bronchodilator FEV1/FVC and FEV1 [15].

Let's not forget our basics; otherwise, we may eventually fail to communicate the important healthcare messages concerning chronic obstructive pulmonary disease.

\section{References}

1. National Institutes of Health, National Heart, Lung and Blood Institute. Global strategy for the diagnosis, management, and prevention of chronic obstructive pulmonary disease. NHLBI/WHO Workshop Report. Publication number 2701, 2001.

2. National Institutes of Health, National Heart, Lung and Blood Institute. Global strategy for the diagnosis, management, and prevention of chronic obstructive pulmonary disease. NHLBI/WHO Workshop Report. Update 2003. www.goldcopd.com

3. Hardie JA, Buist AS, Vollmer WM, Ellingsen I, Bakke PS,
Mùrkve $\mathrm{O}$. Risk of over-diagnosis of COPD in asymptomatic elderly never-smokers. Eur Respir J 2002; 20: 1117-1122.

4. Celli BR, Halbert RJ, Isonaka S, Schau B. Population impact of different definitions of airway obstruction. Eur Respir J 2003; 22: 268-273.

5. Donaldson GC, Seemungal TAR, Patel IS, Lloyd-Owen SJ, Wilkinson TMA, Wedzicka JA. Longitudinal changes in nature, severity and frequency of COPD exacerbations. Eur Respir J 2003; 22: 931-936.

6. Vestbo J, Lange P. Can GOLD stage 0 provide information of prognostic value in chronic obstructive pulmonary disease. Am J Respir Crit Care Med 2002; 166: 329-332.

7. Van der Molen T, Willemse BWM, Schokker S, ten Hacken NHT, Postma DS, Juniper EF. Development, validity and responsiveness of the clinical COPD questionnaire. Health Qual Life Outcomes 2003; 1: 13-23.

8. De Marco R, Accordini S, Cerveri I, et al. An international survey of chronic obstructive pulmonary disease in young adults according to GOLD stages. Thorax 2004; 59: 120-125.

9. Lundbäck B, Lindberg A, Lindström M, et al. Not 15 but $50 \%$ of smokers develop COPD? Report from the Obstructive Lung Disease in Northern Sweden Studies. Respir Med 2003; 97: 115-122.

10. Global Strategy for Asthma Management and Prevention. National Institute of Health, National Heart, Lung, and Blood Institute. Revised 2002. www.ginasthma.com

11. Calverley PMA, Burge PS, Spencer S, Anderson JA, Jones $\mathrm{PW}$, for the ISOLDE study investigators. Bronchodilator reversibility testing in chronic obstructive pulmonary disease. Thorax 2003; 58: 659-664.

12. Chanez P, Vignola AM, O'Shaugnessy $\mathrm{T}$, et al. Corticosteroid reversibility in COPD is related to features of asthma. Am J Respir Crit Care Med 1997; 155: 1529-1534.

13. European Respiratory Society/European Lung Foundation. European Lung White Book. The First Comprehensive Survey on Respiratory Health in Europe. R. Loddenkemper, G.J. Gibson, Y. Sibille, eds. Sheffield, UK, ERSJ, 2003.

14. Croxton TL, Weinmann GG, Senior RM, Wise RA, Crapo JD, Buist AS. Clinical research in chronic obstructive pulmonary disease: needs and opportunities. Am J Respir Crit Care Med 2003; 167: 1142-1149.

15. Celli BR, MacNee W and ATS/ERS Committee Members. Standards for the diagnosis and treatment of patients with COPD: a summary of the ATS/ERS position paper. Eur Respir $J$ 2004; 23 (in press). 